\title{
Global warming decreases the morphological traits of germination and environmental suitability of Dipteryx alata (Fabaceae) in Brazilian
} Cerrado

\section{Raquel Menestrino Ribeiro ${ }^{1}$ (D), Geizianne Tessarolo² (D), Thannya Nascimento Soares ${ }^{1}$ (1), Itamar Rosa Teixeira ${ }^{1}$ (i) and João Carlos Nabout ${ }^{1 *}$ (1)}

Received: August 22, 2018

Accepted: April 8, 2019

\begin{abstract}
We experimentally evaluated how different temperatures affect germination of individual seedlings of Dipteryx alata, and estimated the impact of climate change on the species using ecological niche modeling. A total of 240 seeds were randomly distributed among three different temperature treatments $\left(32^{\circ} \mathrm{C}, 36^{\circ} \mathrm{C}\right.$, and $\left.40{ }^{\circ} \mathrm{C}\right)$, and monitored for 35 days. We measured seven seed traits and estimated the ecological niche of $D$. alata using a consensus of four methods. The treatment with the highest temperature produced smaller and lighter seedlings. The consensus of ecological niche modeling indicated that are expected to reduce the areas with climates favorable for $D$. alata in future scenarios. Thus, our two results (experiment and ecological niche modeling) are concordant, and both indicate the impact of global warming on germination (initial stage of the plant) and potential geographic distribution. Moreover, in geographic context, our experiment and ecological niche modeling indicated that north, northwest and central regions of the "Cerrado" are predicted to have lower morphological traits of germination and loss climate favorable area, since these regions are predicted to have higher temperatures (nearly $40^{\circ} \mathrm{C}$ ) in future climatic scenarios.
\end{abstract}

Keywords: climatic scenarios, germination, global climate change, ecological niche model, temperature

\section{Introduction}

Anthropogenic global climate change is one of the main threats to harvest sustainable (e.g., Nabout et al. 2016), ecosystem services (Scholes 2016), food security (Caetano et al. 2018), and human health (Patz et al. 2005). Moreover, climate change can affect different biological hierarchical levels of species, such as their morphological, functional, demographic, and population traits (McLean et al. 2016). These hierarchical levels may be associated, where the change in one level, for example, physiological traits (e.g., changes in germination or flowering), may affect demographic aspects (such as reproductive success and growth rates) and consequently population aspects (e.g., population size and local extinction); on the other hand, associations between these relationships may not be clear (see Felton \& Smith 2017). To understand the impacts of climate change on biodiversity, it is important to develop studies that integrate different hierarchical levels of species.

Climate has a large effect on plant recruitment, especially during the establishment and initial stages of plant development (Faria et al. 2015). Plants are known to be more sensitive to climate change than other organisms (e.g.

1 Universidade Estadual de Goiás, 75132-903, Anápolis, GO, Brazil

2 Universidade Federal de Goiás, 74690-900, Goiânia, GO, Brazil

* Corresponding author: joao.nabout@ueg.br 
Weltzin \& McPherson 2000; Lloret et al. 2009); moreover, for plants in individual hierarchical levels, climate change can affect the germination attributes of certain species. For example, temperature affects the seed's water absorption and the biochemical reactions that determine the entire germination process (Bewley \& Black 1994; Urbanova \& Leubner-Metzger 2016). During optimum temperature conditions, the plant reaches its maximum germination potential (Mayer and Poljakoff-Mayber 1989). However, when subjected to extreme temperatures, reaction speed tends to increase, causing the seed to germinate earlier, decreasing the survival rate of the seedlings; however, the adult does not present vigorous attributes (Weitbrecht et al. 2011; Flores et al. 2014). Thus, depending on the species, climate change can decrease or increase germination rates or cause a delay in the germination time. These changes at the individual level can be transferred to the population and community levels, changing species distribution, which can have significant ecological and economic impacts (Walck et al. 2011).

At the population level, climate change may affect the geographic distribution of species since climatic features (e.g., temperature and precipitation) are important when defining the limits of species occurrence. Therefore, climate change can increase, reduce, or displace the geographic distribution of species until new areas become climatically suitable or available. The geographic distribution of species is a measure frequently evaluated in studies on global warming (Vaz \& Nabout 2016), and many recent studies have used ecological niche models to evaluate the impact of global climate change on species distribution (see Peterson et al. 2011; Nemésio 2016; Lamsal et al. 2018; Faleiro et al. 2018).

These correlative models associate the sites of species occurrence with certain climatic conditions in order to project the ecological niche model in a biogeographical unit (see Peterson et al. 2011). The models can be designed for different climatic scenarios (e.g., past and future). Recent studies have shown that species from the "Cerrado" can reduce or displace their geographic distribution in future scenarios of climate change (Collevatti et al. 2013). Ecological niche models demonstrated that the occurrence of Dipteryx alata, an important plant in the Cerrado biome, is currently indicative of high habitat adequacy in the "Cerrado" (Nabout et al. 2010; Soares et al. 2015). However, the effects of a changing climate are giving this species the tendency to migrate to the southeast of Brazil (Diniz-Filho et al. 2015).

Dipteryx alata is a tree of the family Fabaceae, popularly known as Baru. It is a deciduous plant in a late secondary succession stage, meaning that the plant develops well under shade (Queiroz \& Oliveira 2014). Dipteryx alata occurs on the well-drained soils of the Cerrado Biome (see details of this biome in Ribeiro and Walter 1998). The species is abundant throughout the Cerradão, a semi-deciduous forest with areno-clay soils (Filgueiras \& Silva 1975). In addition, studies of phylogeographic and genetic diversity suggest that the species dispersal center is located in the western region of the Cerrado Biome (Collevatti et al. 2013; Soares et al. 2015).

The species $D$. alata has multiple uses, for example, human and animal alimentations, landscaping, and the recovery of degraded areas (Almeida et al. 1998; Nabout et al. 2010; Queiroz \& Oliveira 2014). Therefore, when the tree's fruit is commercialized, the species will have importance for local economies. Considering the possible impacts of climate change at the different hierarchical levels on biodiversity, the aim of this paper was estimate the impact of climate change on the different hierarchical levels of $D$. alata. Here, we evaluate the effects of different temperatures on the germination traits of individual $D$. alata seeds. Additionally, we estimate the impact of climate change on environmental suitability of D. alata using ecological niche modeling techniques. The hypotheses for the present study were as follows: i) Temperature affects $D$. alata seed germination, reducing the weight of germinated plants at higher temperatures, and ii) geographic areas with the greatest loss of environmental suitability of $D$. alata are the hottest and therefore also present decreased germination traits (e.g., weight and length). This hypothesis is based on the importance of temperature to the different hierarchical levels.

\section{Materials and methods}

\section{Sampling Dipteryx alata fruit}

Dipteryx alata Vogel fruits were harvested in August and September of 2015 in the germplasm collection at the School of Agronomy of the Universidade Federal de Goiás, Brazil. The trees originate from 25 municipalities within the "Cerrado" Biome (the districts of Goiás, Mato Grosso, Mato Grosso do Sul, Tocantins, Minas Gerais and São Paulo). The location of the fruits used in the experiment also differed according to the type of environment in which they were found, i.e., pasture, cerradão, dry forest, or a combination of these environments. The use of a germplasm collection allows access to a greater genetic diversity, guaranteeing that the largest number of genotypes are grouped in the same place.

Fruits were collected from 10 phenotypically superior trees. We collected the fruit samples according to the appropriate period of fruit physiological maturation. This corresponds to the time when the fruit easily detaches from the branches or to fruits that already detached and are in the soil under the tree canopy. The seeds were subjected to a post-maturation period of 60 days, necessary to guarantee sufficient seed germination (Correa et al. 2000; Zaidan \& Carreira 2008). Fruit was cut with a knife to extract the seeds. The seeds were packed in a greenhouse at constant temperature of $12{ }^{\circ} \mathrm{C}$ in order to conserve vigor. Afterwards, seeds were selected according to their physiological characteristics: seeds 


\section{Raquel Menestrino Ribeiro, Geizianne Tessarolo, Thannya Nascimento Soares, Itamar Rosa Teixeira and João Carlos Nabout}

that had caterpillars, that had been attacked by insects, and that had physical damage were all discarded. Seeds from all the trees were mixed and homogenized in order to create a batch that represented the entire population. The seeds were disinfested with $2 \%$ sodium hypochlorite for five minutes and then washed with distilled water to eliminate pathogens. We performed dormancy breakage with water at $90^{\circ} \mathrm{C}$, immersing the seeds for five minutes.

\section{Experimental design}

A total of 240 seeds were randomly distributed between three different temperatures $\left(32^{\circ} \mathrm{C}, 36^{\circ} \mathrm{C}\right.$, and $40^{\circ} \mathrm{C}$ ). Therefore, each group had 80 replicates (seeds). Each seed was placed in a container with soil (red and sand Latosol) and sterilized. The seeds were irrigated during the experiment, which consisted of watering every three days until the soil reached $60 \%$ of its water retention capacity, as proposed by Brasil (1992).

The trays were distributed in three BOD (Biochemical Oxygen Demand) incubators to simulate temperature (see details below) and were randomized at the time of irrigation in order to eliminate possible site effects. The photoperiod was 12-12 h (dark-light). The experiment was carried out between May and June of 2016, with a duration of 35 days. After this period, the seedling had completely formed.

We used three temperature conditions $\left(32{ }^{\circ} \mathrm{C}, 36^{\circ} \mathrm{C}\right.$ and $40{ }^{\circ} \mathrm{C}$ ), representing moderate, hot and very hot temperatures, respectively. To define experimental temperatures conditions for the experiment, temperature data were obtained for current and future climate scenarios (CCSM project for 2100) from the EcoClimate platform (Lima-Ribeiro et al. 2015). Among the available temperature variables (11 bioclimatic variables), the temperature in the hottest month (BIO05) was selected because it corresponds with temperatures normally observed during D. alata germination in the "Cerrado" biome. This species germinate during summer period, characterized by high temperature and soil water availability (Saboya \& Borghetti 2012). Moreover, the temperature in the "Cerrado" biome varies spatially and temporally. Therefore, these temperature was selected based on both the spatial and temporal intervals of the climatic temperature scenarios in the Cerrado biome. The temperatures used in the experiment allow for evaluation of how spatial variations in temperature can affect species germination. Theses temperatures are registered in the Cerrado Biome or are from future climate scenarios. Current and future temperature maps (BIO05) for the Cerrado biome are available in Figure $\mathrm{S} 1$ in supplementary material.

We considered that germinated seeds have these characteristics during the analysis: normal eophyll, a radicle system with main root, and a secondary root without necrosis. We measured the following morphological germination traits: total weight (TW), fresh root weight (FRW), fresh eophyll weight (FEW), fresh leaf weight (FLW), total length (TL), maximum root length (MRL), and length of the eophyll (LE). The weight trait are in grams, and length in millimeters.

\section{Ecological niche modeling}

We used ecological niche modeling (ENM) techniques to estimate the geographic distribution of D. alata in current and future climate scenarios. Several parameters were necessary for the development of the models: (a) geographic coordinates of species occurrence and (b) current and future climate data. Geographical coordinate data for D. alata were compiled via scientific collections available on the CRIA website, within the species link network (http://splink.cria. org.br), GBIF (www.gbif.org) and scientific literature. We used only geographical coordinates that correspond to site of sampling, thus, geographical coordinates of municipalities or inaccuracies were not included in the models. A total of 531 geographical coordinates were used for the elaboration of the model (Fig. 1). The occurrence points were associated with a $0.5^{\circ} \times 0.5^{\circ}$ latitudinal and longitudinal grid, which was the resolution of the original climatic data (see below). Each occurrence point occupied unique cell grid, thus, duplicate was removed. Climatic variables from actual and future climate scenarios (projected to 2070) were obtained from the WorldClim database (available at www.worldclim.org) at resolution of 10 arc-minutes, and resampling to resolution of of $0.5^{\circ} \times 0.5^{\circ}$ from latitude and longitude. Future climatic conditions for 2070, were based on the RCP8.5 emission scenarios, which were derived from four coupled Atmosphere-Ocean General Circulation Models (AOGCM). These were the Community Climate System Model (CCSM4), Centre National de Recherches Météorologiques (CNMRCM5), Marine-Earth Science and Technology-National Institute for Environmental Studies (MIROC-ESM) and the Meteorological Research Institute (MRI-CGCM3). To evaluate the ecological niche model of $D$. alata in biome Cerrado we generated three maps: actual climate scenarios, future climate scenarios, and delta climate suitability. The delta suitability correspond the subtraction of the future model minus the current model, thus, positive values indicate the gain of suitability, negative values indicate loss, and values near zero indicate stable areas.

To account for colinearity among climatic variables, we performed a Variance Inflation Factor (VIF) with all 19 climatic variables. We selected variables with VIF less than two. We used the "vifstep" function available in package usdm in software R (R Development Core Team 2018). The variables selected were Precipitation Seasonality (Coefficient of Variation), Precipitation of Warmest Quarter, Precipitation of Coldest Quarter, Mean Diurnal Range, Isothermality and Mean Temperature of Wettest Quarter. These variables were used as initial conditions in order to generate ENM for the D. alata in the present and future climate scenarios. 
To make predictions about the distribution of D. alata, we used a combination of four ENM techniques: generalized linear models (GLM; McCullagh \& Nelder 1989), maximum entropy modeling (MaxEnt; Phillips et al. 2006), random forest (Breiman 2001), and classification and regression trees (CART). Occurrence data for D. alata were split into proportions of $70 \%$ to calibrate the models and $30 \%$ for validation. The number of pseudo-absence varied depending of the ENM. To MaxEnt and GLM we generated 2000 pseudo-absences randomly chosen from the entire study area, while for CART and Randon Forest we selected the same amount of pseudo-absence as the amount of available presences (see Barbet-Massin et al. 2012). This procedure was repeated 10 times for each modeling technique.

To evaluate the performance of the models, we used two metrics: true skill statistic (TSS; Allouche et al. 2006) and area under the ROC curve (AUC; Fielding \& Bell 1997). These metrics represent the most utilized measures to assess ecological niche model performance; thus, using these metrics allows for comparability among studies. To calculate the threshold-based metrics, we used the threshold that maximizes the sum of sensitivity and specificity for each model. The final model (consensus), was generated by the calculation of the weighted mean of suitability of the all models. The weighted was based in sensitivity of each model. All ecological niche models were built using functions in the sdm package (Naimi \& Araújo 2016) in software R.

\section{Data analysis}

From the 240 total seeds, 108 germinated (corresponding to $45 \%$ of the total) and were therefore used for morphological measurements of seedling weight and length. We analyzed the colinearity between germination traits by using the variation inflation factor (VIF) test. All variables had a VIF of less than 7 , indicating the absence of colinearity (Belsley et al. 2005). Thus, all variables were

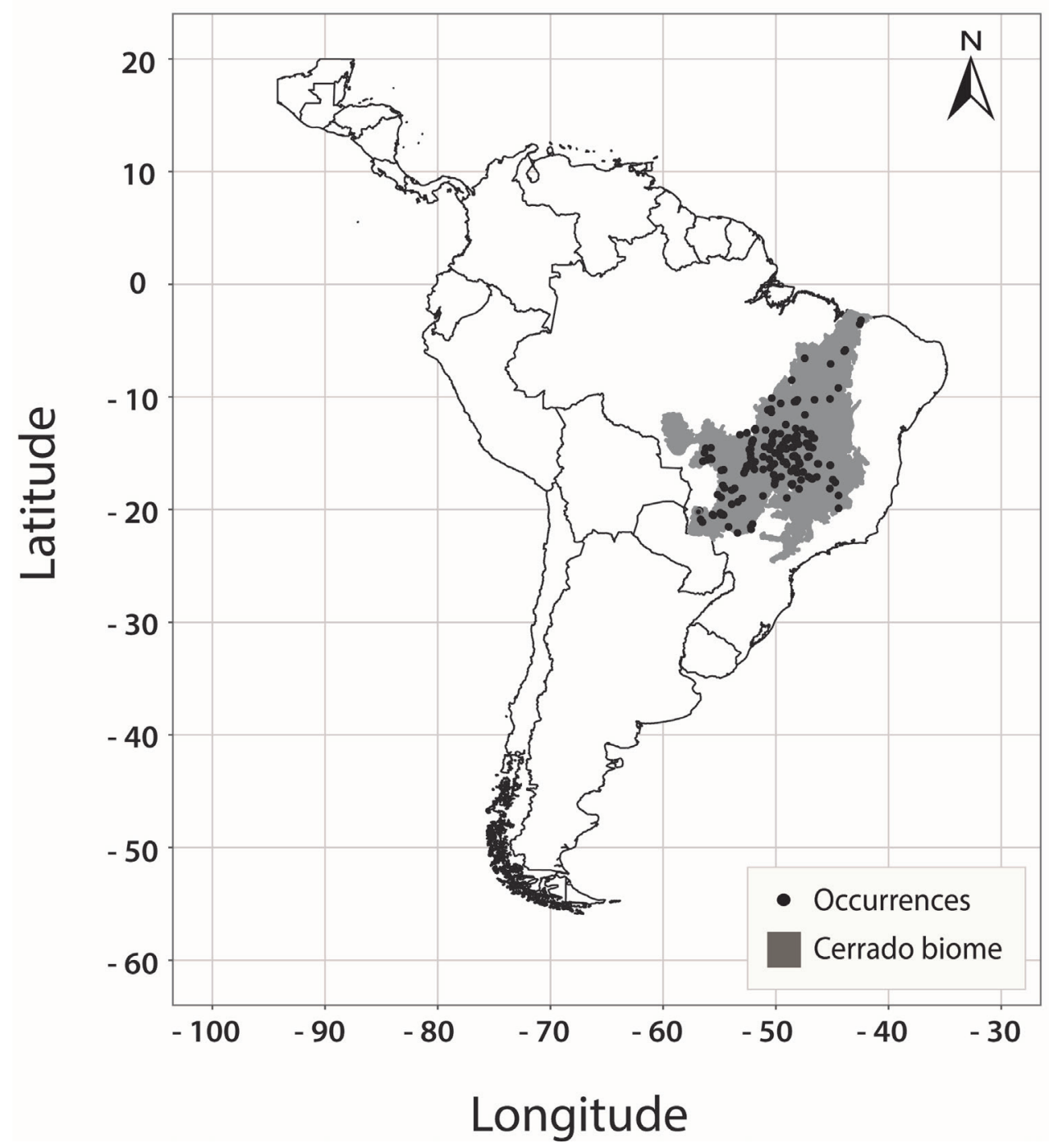

Figure 1. Occurrences of $D$. alata used to generate the species distribution models and the limits of the Cerrado Biome. 
used in the data analysis stage. We tested the influence of temperature on germination traits using permutational analysis of variance (PERMANOVA; Anderson \& Walsh 2013). The assumption of homogeneity of covariance of the groups in PERMANOVA was not violated $(\mathrm{F}=0.36$; $\mathrm{P}=0.69$ ). Afterwards a linear discriminant function analysis was performed to evaluate the relationships of each trait of germination and the varying temperatures. For these analyzes, the data were log-transformed. All statistical tests were performed in the R program, in which PERMANOVA was carried out in the vegan package (Oksanen et al. 2016), VIF in the faraway package (Faraway et al. 2016), and the discriminant analysis in the MASS package (Venables \& Ripley 2002). The assumption of PERMANOVA was test used the function betadisper in vegan package.

\section{Results}

The number of germinated seeds varied among the treatments: at $32^{\circ} \mathrm{C}, 42 \%$ of the seeds germinated (a total of 80 seeds); at $36^{\circ} \mathrm{C}, 68.7 \%$ germinated; and at $40^{\circ} \mathrm{C}, 23 \%$ of the seeds germinated. Therefore, the $36{ }^{\circ} \mathrm{C}$ treatment showed higher rates of germination. Seven traits were measured after germination, and these varied for each temperature condition (Tab. 1). In fact, PERMANOVA indicated that the seeds presented significant differences in germination trait according to the different temperature levels (Tab. 2).

In addition, seedlings subjected to the $40{ }^{\circ} \mathrm{C}$ treatment exhibit different morphological traits of germination compared with the $32{ }^{\circ} \mathrm{C}$ and $36{ }^{\circ} \mathrm{C}$ treatments (Fig. 2). The first axis demonstrates a greater dispersion in the morphological traits of germination at a temperature of $36^{\circ} \mathrm{C}$. On the other hand, for the hottest treatment $\left(40^{\circ} \mathrm{C}\right)$, the morphological traits of germination presented low variation (which can be observed by the small dispersion of points). Moreover, in the hottest treatment, the seedlings were smaller and weighed less (Tab. 1), as indicated by negative correlations between the values of "Total weight" and "Maximum root length," with the first axis as the linear discriminant (Tab. 3).

The ecological niche model suggests all Cerrado biome and outside of Cerrado (western region) currently favors the occurrence of $D$. alata. However, for future scenarios, areas in the Cerrado with climates favorable for $D$. alata growth are expected to reduce. The areas of reduced environmental suitability concentrate around the north, northwest and central region of the biome, whereas in the southeastern segments of the Cerrado, there will be a small increase in climate suitability (Fig. 3). All models used in consensus presented higher metrics values, indicated good models (Tab. 4), and each replicate presented similar metrics (indicated by small standard deviation).

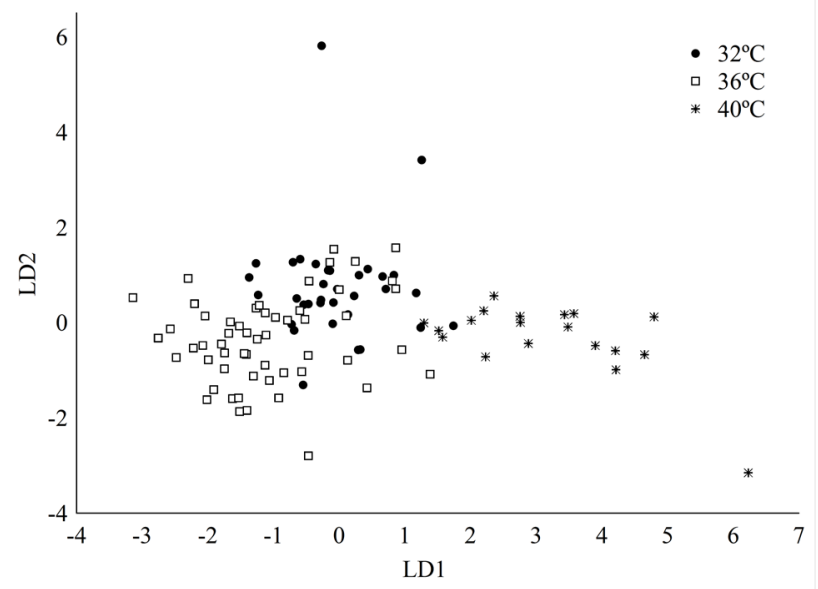

Figure 2. A plot of the linear discriminant analysis, indicating dispersion of experimental units in two dimensions (LD1 and LD2). These two components accounted for $99.9 \%$ of the total changes in the data.

\section{Discussion}

The present study evaluated the impact of global climate change on morphological traits of germination and the ecological niche model of $D$. alata in the Cerrado biome. Our results indicate that these two hierarchical levels are affected by climate change. In warmer environments, this species presented lower total weight and lower maximum root length. In addition, with climate change, the geographic distribution of the $D$. alata species tends to decrease in the Cerrado biome. Thus, the presented paper integrated results in different scale of hierarchical organization (impact on local germination trait, and impact on geographical

Table 1. Statistical summary (average and standard deviation - SD) of germination morphological traits for each treatment.

\begin{tabular}{|c|c|c|c|c|c|c|}
\hline \multirow{2}{*}{ Traits } & \multicolumn{2}{|c|}{$32^{\circ} \mathrm{C}$} & \multicolumn{2}{|c|}{$36{ }^{\circ} \mathrm{C}$} & \multicolumn{2}{|c|}{$40^{\circ} \mathrm{C}$} \\
\hline & Average & SD & Average & SD & Average & SD \\
\hline Total weight & 2.05 & 0.68 & 2.00 & 0.64 & 1.05 & 0.36 \\
\hline Fresh root weight & 0.45 & 0.30 & 0.59 & 0.38 & 0.09 & 0.05 \\
\hline Fresh eophyll weight & 1.32 & 0.56 & 1.27 & 1.35 & 0.84 & 0.30 \\
\hline Fresh leaf weight & 0.28 & 0.16 & 0.30 & 0.29 & 0.11 & 0.11 \\
\hline Total length & 157.95 & 59.78 & 270.80 & 91.62 & 91.96 & 23.55 \\
\hline Maximum root length & 58.04 & 29.60 & 153.05 & 83.83 & 16.24 & 12.68 \\
\hline Length of the eophyll & 79.67 & 33.35 & 93.07 & 30.87 & 58.54 & 16.89 \\
\hline
\end{tabular}


(A) Present suitability

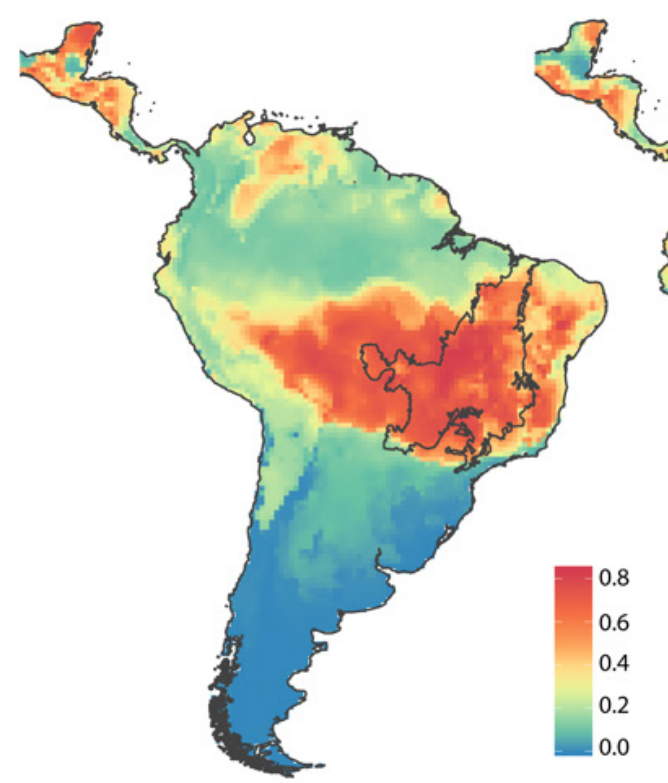

(B) Future suitability

(C) Delta suitability

Figure 3. Maps of climatic suitability for Dipteryx alata in two climate scenarios: A. present, B. future (year 2070), and C. the delta of environmental suitability for $D$. alata, where positive values indicate the gain of suitability, negative values indicate loss, and values near zero indicate stable areas.

Table 2. The results of the PERMANOVA with all germination morphological traits for comparison with the three temperatures.

\begin{tabular}{|c|c|c|c|c|}
\hline & Degree Freedom & F & R2 & P \\
\hline Temperature & 2 & 39.5 & 0.43 & 0.001 \\
\hline Residual & 105 & & 0.57 & \\
\hline Total & 107 & & 1 & \\
\hline
\end{tabular}

Table 3. Loading of the linear discriminant analysis, indicating the relationship of each morphological germination trait with the LD axis.

\begin{tabular}{|c|c|c|}
\hline \multicolumn{3}{|c|}{ Coefficients of Linear Discriminant Analysis } \\
\hline & LD1 & LD2 \\
\hline Total weight & -0.83 & 0.23 \\
\hline Fresh root weight & -0.69 & 0.90 \\
\hline Fresh leaf weight & -0.27 & 0.35 \\
\hline Fresh eophyll weight & 0.29 & 0.48 \\
\hline Total length & 0.19 & -1.45 \\
\hline Maximum root length & -0.95 & -0.34 \\
\hline Length of the eophyll & -0.33 & -0.25 \\
\hline
\end{tabular}

Table 4. Mean values and standard deviation (SD) of evaluation metrics based on four ecological niche models generated for Dipteryx alata. To each ecological niche model were generated ten different models, based on the random splitting of the observation data in $70 \%$ for prediction and $30 \%$ for evaluation (see details in Materials and methods).

\begin{tabular}{|c|c|c|c|c|}
\hline \multirow{2}{*}{ Methods } & \multicolumn{2}{|c|}{ AUC } & \multicolumn{2}{c|}{ TSS } \\
\cline { 2 - 5 } & Mean & SD & Mean & SD \\
\hline MaxEnt & 0.989 & 0.004 & 0.957 & 0.022 \\
\hline GLM & 0.941 & 0.012 & 0.854 & 0.033 \\
\hline Randon Forest & 0.984 & 0.010 & 0.927 & 0.032 \\
\hline CART & 0.959 & 0.022 & 0.879 & 0.042 \\
\hline
\end{tabular}

distribution) and, therefore more completed understanding about the impact of climate change on vegetal biodiversity.

The experimental study indicated that some traits of germination tend to reach a maximum at temperatures near $36{ }^{\circ} \mathrm{C}$. This is a common reaction in most biological systems, where temperature increases result in increased reaction rates (Flores et al. 2014). On the other hand, exposure to temperatures above the maximum germination temperature for long periods of time can compromise metabolic processes due to the risk of protein denaturation (Hoekstra et al. 2001).

The influence of temperature on the fresh weight of a seedling can be attributed to the influence of heat during the development of initial structures, such as the primary root system (Probert 2000; Weitbrecht et al. 2011). The root is the first structure to develop and is essential to establishing the seedling in its environment. Thus, with inappropriate temperatures, cell division processes are affected, leading to a decrease in the developmental capacity and resulting in seedlings with lower dry matter content (e.g. Oliveira et al. 2014).

Temperature is an influential factor during phenological events that alter the population structure (Jay et al. 2012). To avoid local extinction due to global warming, plant populations may respond by means of phenotypic plasticity, by adaptation to new climate conditions selecting specific genetic variations and mutations, or by migrating plants to new locations where local climate conditions are favorable for growth (Aitken et al. 2008). Thus, the temperature can affect different hierarchical organization levels of species, including the potential geographic distributions in large geographic scale. 


\section{Raquel Menestrino Ribeiro, Geizianne Tessarolo, Thannya Nascimento Soares, Itamar Rosa Teixeira and João Carlos Nabout}

The geographic distribution of a species depends on the relationships among the biotic, abiotic, and historical factors, and climate plays a fundamental role in this distribution (Peterson et al. 2011; Cunha et al. 2018). According to the current map of ecological niche model, this species presented broad climatic suitability area. Moreover our predictions of climatic suitability area of $D$. alata indicate the tendency toward migration to the southern region and reduce the climate suitability area in north, northwest and central regions of Cerrado. Most studies of plants have demonstrated a reduction in the potential geographical distribution for future scenarios (Collevatti et al. 2011; Mendoza-González et al. 2013). However, some species show the opposite, such as Euterpe oleracea (Arecaceae), which presented an increased distribution in future scenarios, although relatively small (Vaz \& Nabout 2016); this can be attributed to environmental and physiological plant variables.

Plant populations may not adapt well to new climate conditions; instead, species can migrate to new suitable areas (Anderson \& Walsh 2013). However, these new areas should be similar to the original area in terms of environmental factors, such as the photoperiod and humidity (Shaw \& Etterson 2012), as well as important mutualisms, such as pollinators, which ensure the species' successful adaption to new areas. Another troublesome factor is the state of land use in the new potential areas for D. alata (in future scenarios). The ecological niche model used here produces conservative results because other variables such as land use were not considered (Hannah et al. 2002; Cunha et al. 2018). This is especially important considering that the Cerrado has experienced intense occupation and land use conversion, mainly for grazing and agriculture (e.g., soybeans and sugar cane) (Sawyer 2008). Moreover, secondary species, such as D. alata, tend to be more vulnerable in the early stages of growth, necessitating the ecological balance in order for the plants to become established. Thus, it is possible that $D$. alata can find occurrences of other factors, such as rainfall and soils with different or converted land use, in new areas.

The results of the impact of global warming on morphological traits of germination and the ecological niche model are in good agreement. In other words, the regions that are less suitable (i.e., the north and northwest) in the "Cerrado" should have lower morphological traits of germination since these regions tend to have higher temperatures in future climatic scenarios (see Fig. S1 in supplementary material). Moreover, in the regions of increased suitability (i.e., southern regions of the biome, and outside of Cerrado), the temperature was beneficial for D. alata germination. However, these regions are some of the most impacted areas of the biome, which can hinder D. alata occurrence.

Therefore, in future climate change studies, it is important to assess the impact of climate change on the different hierarchical levels of biodiversity since climatically favorable areas according to an ecological niche model (for a hierarchical population level) may not adequately represent the ideal conditions for species germination (physiological hierarchical level). Particularly for D. alata, in future climate scenarios, the higher temperature expected in some regions of Cerrado (e.g. north, northwest and central) present poor climatic conditions for germination, as well as low climatic suitability indicated by the ecological niche model. Therefore, the continued presence of this species in this region requires appropriate management for these conditions. On the other hand, the most suitable regions, when considering the niche model and germination conditions (i.e., the south region), require careful selection of areas where species conservation will occur, since this is the very converted land use region in the Cerrado biome.

\section{Acknowledgements}

We thank the anonymous reviewer and Elias E. S. Mota for criticisms that improved the manuscript. This study was supported by CNPq, CAPES Finance Code 001, FAPEG, National Institutes for Science and Technology (INCT) in Ecology, Evolution and Biodiversity Conservation and Brazilian Network on Global Climate Change Research (Rede CLIMA). RMR received a scholarship from CAPES. JCN, TNS and IRT were supported by a CNPq productivity grant. GT was supported by PNPD/CAPES postdoc fellowship number PNPD20132984-52012018005P7.

\section{References}

Aitken SN, Yeaman S, Holliday JA, Wang T, Curtis-Mclane S. 2008. Adaptation, migration or extirpation: climate change outcomes for tree populations. Evolutionary Applications 1: 95-111.

Allouche O, Tsoar A, Kadmon R. 2006. Assessing the accuracy of species distribution models: prevalence, kappa and the true skill statistic (TSS). Journal of Applied Ecology 43: 1223-1232.

Almeida SD, Proença CE, Sano SM, Ribeiro JF. 1998. Cerrado: espécies vegetais úteis. Planaltina, Embrapa-CPAC.

Anderson MJ, Walsh DC. 2013. Permanova, Anosim, and the Mantel test in the face of heterogeneous dispersions: what null hypothesis are you testing? Ecological Monographs 83: 557-574.

Barbet-Massin M, Jiguet F, Albert CH, Thuiller W. 2012. Selecting pseudoabsences for species distribution models: How, where and how many? Methods in Ecology and Evolution 3: 327-338.

Belsley DA, Kuh E, Welsch RE. 2005. Regression diagnostics: Identifying influential data and sources of collinearity. New Jersey, John Wiley \& Sons.

Bewley JD, Black M. 1994. Seeds: physiology of development and germination. 2nd. edn. New York, Plenum.

Brasil. 1992. Regras para análises de sementes. Brasília, SNDA/DNDV/ CLAV.

Breiman L. 2001. Random forests. Machine Learning 45: 5-32.

Caetano JM, Tessarolo G, Oliveira G, Souza KDS, Diniz-Filho JAF, Nabout JC. 2018. Geographical patterns in climate and agricultural technology drive soybean productivity in Brazil. PLOS ONE 13(1): e0191273. doi: 10.1371/journal.pone.0191273

Collevatti RG, Nabout JC, Diniz-Filho JAF. 2011. Range shift and loss of genetic diversity under climate change in Caryocar brasiliense, a Neotropical tree species. Tree Genetics \& Genomes 7: 1237-1247. 


\section{Global warming decreases the morphological traits of germination and environmental suitability of Dipteryx alata (Fabaceae) in Brazlian Cerrado}

Collevatti RG, Telles MPC, Nabout JC, Chaves LJ, Soares TN. 2013. Demographical history and the low genetic diversity in Dipteryx alata (Fabaceae) from Brazilian Neotropical savannas. Heredity 111: 97-105.

Correa GC, Rocha MR, Naves RV. 2000. Germinação de sementes e emergência de plântulas de baru (Dipteryx alata Vog.) Cerrados do Estado de Goiás. Pesquisa Agropecuária Tropical 30: 17-23.

Cunha HF, Ferreira ED, Tessarolo G, Nabout JC. 2018. Host plant distributions and climate interact to affect the predicted geographic distribution of a neotropical termite. Biotropica 50: 625-632.

Diniz-Filho JAF, Rodrigues H, Terribile LC, et al. 2015. Correlation between genetic diversity and environmental suitability: taking uncertainty from ecological niche models into account. Molecular Ecology Resources 15: 1059-1066.

Faleiro FV, Nemésio A, Loyola R. 2018. Climate change likely to reduce orchid bee abundance even in climatic suitable sites. Global Change Biology 24: 2272-2283.

Faraway J. 2016. Faraway: functions and datasets for books by Julian Faraway. R package version 1.0.7. https://CRAN.R-project.org/ package $=$ faraway

Faria AP, Fernandes GW, França MGC. 2015. Predicting the impact of increasing carbon dioxide concentration and temperature on seed germination and seedling establishment of African grasses in Brazilian Cerrado. Austral Ecology 40: 962-973.

Felton AJ, Smith MD. 2017. Integrating plant ecological responses to climate extremes from individual to ecosystem levels. Philosophical Transactions of the Royal Society B: Biological Sciences 372(1723): 20160142. doi: 10.1098/rstb.2016.0142

Fielding AH, Bell JF. 1997. A review of methods for the assessment of prediction errors in conservation presence/absence models. Environmental Conservation 24: 38-49.

Filgueiras TS, Silva E. 1975. Estudo preliminar do baru (Leg., Fabiodeae). Brasil Florestal 6: 33-39.

Flores AV, Borges EEDL, Guimarães VM, Gonçalves JFDC, Ataíde GD, Barros DDP. 2014. Atividade enzimática durante a germinação de sementes de Melanoxy lonbrauna Schott sob diferentes temperaturas. Cerne 20: 401-408.

Hannah L, Midgley GF, Millar D. 2002. Climate change-integrated conservation strategies. Global Ecology and Biogeography 11: 485-495.

Hoekstra FA, Golovina EA, Buitink J. 2001. Mechanisms of plant desiccation tolerance. Trends in Plant Science 6: 431-438.

Jay F, Manel S, Alvarez N, et al. 2012. Forecasting changes in population genetic structure of alpine plants in response to global warming. Molecular Ecology 21: 2354-2368.

Lamsal P, Kumar L, Aryal A, Atreya K. 2018. Invasive alien plant species dynamics in the Himalayan region under climate change. Ambio 1-14.

Lima-Ribeiro MS, Varela S, González-Hernández J, Oliveira G, DinizFilho JAF, Terribile LC. 2015. EcoClimate: a databaseofclimate data frommultiplemodels for past, present, and future for Macroecologists and Biogeographers. Biodiversity Informatics 10: 1-21.

Lloret F, Peñuelas J, Prieto P, Llorens L, Estiarte M. 2009. Plant community changes induced by experimental climate change: seedling and adult species composition. Perspectives in Plant Ecology, Evolution and Systematics 11: 53-63.

Mayer AC, Poljakoff-Mayber A. 1989. The germination of seeds. Oxford, Pergaman Press.

McCullagh P, Nelder JA. 1989. Generalized linear models. London, Chapman and Hall.

McLean N, Lawson CR, Leech DI, Pol M. 2016. Predicting when climatedriven phenotypic change affects population dynamics. Ecology Letters 19: 595-608.

Mendoza-González G, Martínez ML, Rojas-Soto OR, Vázquez G, GallegoFernández JB. 2013. Ecological niche modeling of coastal dune plants and future potential distribution in response to climate change and sea level rise. Global Change Biology 19: 2524-2535.

Nabout JC, Magalhães MR, Gomes MAA, Cunha HF. 2016. The impact of global climate change on the geographic distribution and sustainable harvest of Hancornia speciosa Gomes (Apocynaceae) in Brazil. Environmental Management 4: 814-821.
Nabout JC, Soares TN, Diniz-Filho JAF, et al. 2010. Combining multiple models to predict the geographical distribution of the Baru tree (Dipteryx alata Vogel) in the Brazilian Cerrado. Brazilian Journal of Biology 70: 911-919.

Naimi B, Araujo MB. 2016. "sdm: a reproducible and extensible R platform for species distribution modelling." Ecography 39: 368-375.

Nemésio A, Silva DP, Nabout JC, Varela S. 2016. Effects of climate change and habitat loss on a forest-dependent bee species in a tropical fragmented landscape. Insect Conservation and Diversity 9: 149-160.

Oksanen J, Blanchet FG, Friendly M, et al. 2016. Vegan: community ecology package. R package version 2.4-4. https://CRAN.R-project. org/package= vegan

Oliveira AKM, Ribeiro JWF, Pereira KCL, Silva CAA. 2014. Germinação de sementes de paineira-do-campo (Eriotheca gracilipes (K. Schum.) A. Robyns) em diferentes temperaturas. Científica 42: 316-324.

Patz JA, Campbell-Lendrum D, Holloway T, Foley JA. 2005. Impact of regional climate change on human health. Nature 438: 310-317.

Peterson AT, Soberón J, Pearson RG, et al. 2011. Ecological niches and geographic distributions (MPB-49). New Jersey, Princeton University Press.

Phillips SJ, Anderson RP, Schapire RE. 2006. Maximum entropy modeling of species geographic distributions. Ecological Modelling 190: 231-259.

Probert RJ. 2000. The role of temperature in the regulation of seed dormancy and germination. In: Feener M. (ed.) Seeds: the ecology of regeneration in plant communities. Wallingford, CABI publishing. p. 261-292.

Queiroz SE, Oliveira FT. 2014. Efeito do sombreamento na germinação e desenvolvimento de mudas de baru (Dipteryx alata Vog.). Revista Biociências 20: 72-77.

R Development Core Team. 2018. R: A language and environment for statistical computing. Vienna, R Foundation for Statistical Computing. https://www.R-project.org/

Ribeiro JF, Walter BMT. 1998. Fitofisionomias do bioma Cerrado. In: Sano SM, Almeida SP. (eds.) Cerrado: ambiente e flora. Planaltina, EMBRAPA-CPAC. p. 86-166.

Saboya P, Borghetti F. 2012. Germination, initial growth, and biomass allocation in three native Cerrado species. Brazilian Journal of Botany 35: 129-135.

Sawyer D. 2008. Climate change, biofuels and eco-social impacts in the Brazilian Amazon and Cerrado. Philosophical Transactions of the Royal Society B: Biological Sciences 363: 1747-1752.

Scholes RJ. 2016. Climate change and ecosystem services. Wiley Interdisciplinary Reviews: Climate Change 7: 537-550.

Shaw RG, Etterson JR. 2012. Rapid climate change and the rate of adaptation: insight from experimental quantitative genetics. New Phytologist 195: 752-765.

Soares TN, Diniz-Filho JAF, Nabout JC, Telles MPC, Terribile LC, Chaves LJ. 2015. Patterns of genetic variability in central and peripheral populations of Dipteryx alata (Fabaceae) in the Brazilian Cerrado. Plant Systematics and Evolution 301: 1315-1324.

Urbanova T, Leubner-Metzger G. 2016. Gibberellins and seed germination. Annual Plant Reviews 49: 253-284.

Vaz UL, Nabout JC. 2016. Using ecological niche models to predict the impact of global climate change on the geographical distribution and productivity of Euterpe oleracea Mart. (Arecaceae) in the Amazon. Acta Botanica Brasilica 30: 290295.

Venables WN, Ripley BD. 2002. Modern applied statistics with S. 4th. edn. New York, Springer.

Walck jL, Hidayati SN, Dixon KW, Thompson K, Poschlod P. 2011. Climate change and plant regeneration from seed. Global Change Biology 17: 2145-2161.

Weitbrecht K, Müller K, Leubner-Metzger G. 2011. First off the mark: early seed germination. Journal of Experimental Botany 62: 3289-3309.

Weltzin JF, McPherson GR. 2000. Implications of precipitation redistribution for shifts in temperate savanna ecotones. Ecology 81: 1902-1913.

Zaidan LBP, Carreira R. 2008. Seed germination in Cerrado species. Brazilian Journal Plant Physiology 20: 167-181. 